\title{
Survey of awareness of diabetes mellitus among the Arar population, Northern Border Region of Saudi Arabia
}

Aseel Menwer Alanazi ${ }^{1}$, Nagah Mohamed Abo el-Fetoh ${ }^{2}$, Hanan Khalid Alotaibi ${ }^{1}$, Khalid Ayed Alanazi ${ }^{3}$, Banan Khalid Alotaibi ${ }^{3}$, Sultan Majed Alshammari ${ }^{3}$, Saud Rteamy Alanazi ${ }^{3}$, Meshari Dalaf Alhazmi ${ }^{3}$, Yousef Talal Alshammari ${ }^{3}$, Zaid Qati Alshammari ${ }^{3}$

\author{
${ }^{1}$ Intern, Faculty of Medicine, Northern Border University, Arar, Kingdom of Saudi Arabia \\ ${ }^{2}$ Associate Professor, Community Medicine Department, Faculty of Medicine, Northern Border University, Arar, \\ Kingdom of Saudi Arabia \\ ${ }^{3}$ Medical Student, Faculty of Medicine, Northern University, Arar, Kingdom of Saudi Arabia
}

\section{Type of article: Original}

\begin{abstract}
Background: Diabetes Mellitus (DM) is one of the most widely prevalent diseases in Saudi Arabia. Health education is considered an essential component to improve knowledge and change behavior. People affected by diabetes often have inadequate knowledge about the nature of diabetes, its risk factors and associated complication.

Objectives: The aim of this study was to assess the awareness of the Arar population with various aspects of diabetes mellitus.

Methods: A cross-sectional study was carried out in Arar city, the capital of the Northern Province of Kingdom of Saudi Arabia (KSA). The study was carried out on Saudi nationals from different age groups that were selected by systematic random sampling. Data was collected by means of personal interview with the participants using a pre-designed questionnaire which was administered by the medical students for each diabetic patient. Data were analyzed by SPSS version 15, using descriptive statistics and Chi-square test.

Results: A total of 702 participants were interviewed, among them 201 (28.6\%) males and 501 (71.4\%) females, and most of them (77.8\%) had high educational level, $10.4 \%$ were diabetics, $78.9 \%$ did not have regular checkup visits to the doctor and $58.5 \%$ did not perform any regular exercises, including walking, $60 \%$ thought that DM was due to partial or total decrease in insulin secretion and $12.4 \%$ thought that it was due to excess sweet eating. Additionally, $48.7 \%$ of the respondents thought that lack of exercise and obesity were the major risk factors of DM, 33.2\% thought that it was a genetic disease. The majority (86.3) of the participants believed that the treatment of DM was a combination of healthy diet, exercise and medication and more than half $(63.1 \%)$ said that weight loss and modification of life style were the most important preventive measures of DM. Regarding participants' knowledge about DM complications, $24.5 \%$ knew about retinopathy and loss of vision, $8.3 \%$ knew about retinopathy, loss of vision, low sensation and numbness in extremities, $24.9 \%$ said that symptoms of DM were thirst and frequent urination.

Conclusion: This study recommends that health policy makers conduct more effective health education sessions to increase knowledge of diabetic patients and their caregivers about diabetes and the importance of compliance with its treatment.
\end{abstract}

Keywords: Awareness, Diabetes, Knowledge, Arar City, Northern Saudi Arabia

\section{Introduction}

Diabetes Mellitus (DM) is one of the most widely prevalent diseases, its incidence is increasing, recent estimates that 415 million people aged 20-79 years have had diabetes in 2015, this number is expected to reach 552 million by

\section{Corresponding author:}

Dr. Aseel Menwer Alanazi, Faculty of Medicine, Northern Border University, Arar, Kingdom of Saudi Arabia.

Tel.: +966.504710410, Email: aseelmenwerm@hotmail.com

Received: July 12, 2017, Accepted: August 23, 2017, Published: September 2017

iThenticate screening: August 23, 2017, English editing: September 19, 2017, Quality control: September 22, 2017

(C) 2017 The Authors. This is an open access article under the terms of the Creative Commons Attribution-NonCommercialNoDerivs License, which permits use and distribution in any medium, provided the original work is properly cited, the use is non-commercial and no modifications or adaptations are made. 
2030 (1) and 642 million by 2040. The prevalence of diabetes in Saudi Arabia is of the highest, there were 3.4 million cases of diabetes in Saudi Arabia in 2015. Saudi Arabia is a member of UNO and a signatory to the HFA declaration, the public sector health system in Saudi Arabia has seen a rapid expansion during the last three decades (2). Health education is considered an essential component to improve knowledge and change behavior; there is evidence that people affected by diabetes often have inadequate knowledge about the nature of diabetes, its risk factors and associated complication. If uncontrolled, diabetes mellitus can be the cause of damage to the eyes and potentially cause blindness, damage to the kidneys which may lead to renal failure, and damage to nerves, which could lead to impotence, foot disorders and possible amputation. Furthermore, it can cause an increased risk of heart disease, stroke, and poor blood supply to the limbs (3). Public health centers (PHCs) are considered to be the best places to provide health education to patients and the general population. Most Saudi Citizens are registered at PHCs and have family health records where they can receive all the required primary health care including management and follow up of diabetes mellitus. One of the main elements of PHCs is health education that must empower and motivate people to take informed decisions on activities to ensure attainment of health (2). In the near future, this latent, but imminent, burden on public health could create considerable challenges to the healthcare systems and economies of a great number of developing nations. One of the reasons for this is because a substantial number of people who suffer from DM in these countries are within the reproductive age $(4,5)$. These individuals are the same people who are expected to assist in the development of their nations' economy so as to achieve the approved millennium development goals (3). If these individuals are affected by uncontrolled diabetes mellitus, it could lead to enduring problems which are commonly associated with increased morbidity and mortality $(3,6)$. The aim of this study is to assess the awareness and knowledge of various aspects of diabetes mellitus and its complications among males and females of the Arar community.

\section{Material and Methods}

This study was done during the period from December 2016 to February 2017 in Arar city (the capital of the Northern Province of KSA). A cross-sectional study was carried out and a random, representative sample from male and female Saudi nationals from different age groups were included in the study. We took systemically random samples from the attendees of five randomly chosen primary health care centers, of whom 501 were females and 201 were males. Data were collected by means of personal interview with the participants, after training the medical students for weeks before starting collection of data and research activities, a well-constructed questionnaire translated into Arabic was administered by the medical students for each diabetic patient (male or female) covering the following items: age, sex, residence, education level, physical activity, knowledge of what diabetes is, causes, complications, management and prevention measures of DM, whether the participant has/had a family member who is/was diabetic, duration of illness since diagnosis of diabetes was established, concurrent morbidities with diabetes mellitus. A total of 702 samples were collected; the primary focus of health education was on the risks associated with unhealthy diet, smoking, and physical inactivity. Filled questionnaires were reviewed for completeness and accuracy before data entry, then the data were coded and analyzed by SPSS version 15 (SPSS Inc., Chicago, Illinois, USA) using Chi-square test. This study was reviewed for seeking approval of the Research Ethics Committee of the Faculty of Medicine, Northern Border University. Participants were informed that participation was completely voluntary, a written consent was obtained from each participant before research, no name was recorded on the questionnaires and all of the personal information of participants were kept confidential.

\section{Results}

Table 1 shows the background characteristics of studied participant. A total of 702 participants were interviewed, among them 201 (28.6\%) were males and 501 (71.4\%) were females and most of them (77.8\%) had high educational level. Table 2 shows the percentage of presence of DM and participants' life style. As shown, it was found that the majority of participants $(89.6 \%)$ were free from DM, $78.9 \%$ did not have regular checkup visits to the doctor and $58.5 \%$ did not do regular walking or any other exercises. Most (92.3\%) of the participants had a diabetic relative or friend and more than $60 \%$ had sufficient knowledge about DM. When we asked the participants about their idea about the nature of DM, $60 \%$ of the participants thought that DM was through partial or total decrease in insulin secretion, $21.4 \%$ thought it was through the decrease in the response of body tissue to insulin and $12.4 \%$ thought it was through excess sweet eating. Risk factors, treatment and preventive measures were assessed by asking some questions. As shown in Table 3,48.7\% of the respondents thought that lack of exercise and obesity were the major risk factors of DM, 33.2\%thought that it was a genetic disease when only $3.7 \%$ thought that it was through hypertension. The majority (86.3) of the participants believed that the treatment of DM was a combination of healthy diet, exercise and medication, and more than half (63.1) of the total said that weight loss and modification of life style were the most important preventive measures of DM. 
Table 1. Sociodemographic characters of the study population, Arar, 2016

\begin{tabular}{|l|l|l|l|}
\hline Variables & \multicolumn{2}{|c|}{ Frequency (n=702) } & $\%$ \\
\hline \multirow{3}{*}{ Sex } & Female & 501 & 71.4 \\
\cline { 2 - 4 } & Male & 201 & 28.6 \\
\hline \multirow{4}{*}{ Educational level } & Elementary & 13 & 1.9 \\
\cline { 2 - 4 } & Secondary & 117 & 16.7 \\
\cline { 2 - 4 } & University & 546 & 77.8 \\
\cline { 2 - 4 } & Non & 1 & 3.1 \\
\cline { 2 - 4 } & Intermediate & 25 & \\
\hline
\end{tabular}

Table 2. Percentage of diabetic subjects and life style characteristics of the participants, Arar, 2016

\begin{tabular}{|c|c|c|c|}
\hline \multicolumn{2}{|l|}{ Items of questionnaire } & Frequency $(\mathrm{n}=702)$ & $\%$ \\
\hline \multirow[t]{2}{*}{ Presence of DM } & No & 629 & 89.6 \\
\hline & Yes & 73 & 10.4 \\
\hline \multirow{5}{*}{ Period of having DM (in years) } & No DM & 623 & 88.7 \\
\hline & $>1$ & 19 & 2.7 \\
\hline & $1-5$ & 27 & 3.8 \\
\hline & $6-10$ & 17 & 2.4 \\
\hline & $>10$ & 16 & 2.3 \\
\hline \multirow{2}{*}{$\begin{array}{l}\text { Do you have regular checkup visits to } \\
\text { your doctor? }\end{array}$} & No & 604 & 78.9 \\
\hline & Yes & 98 & 14.0 \\
\hline \multirow[t]{4}{*}{ Physical exercise } & Regular walking & 89 & 12.7 \\
\hline & Irregular walking and other exercise & 411 & 58.5 \\
\hline & No exercise & 202 & 28.8 \\
\hline & Regular walking and other exercise & 89 & 12.7 \\
\hline \multirow[t]{2}{*}{ Having diabetic relative or friend } & No & 54 & 7.7 \\
\hline & Yes & 648 & 92.3 \\
\hline \multirow[t]{2}{*}{ Having knowledge about DM } & No & 251 & 35.8 \\
\hline & Yes & 451 & 64.2 \\
\hline \multirow{2}{*}{$\begin{array}{l}\text { Attending health education sittings and } \\
\text { benefit from its brochures }\end{array}$} & No & 452 & 64.4 \\
\hline & Yes & 250 & 35.6 \\
\hline \multirow[t]{4}{*}{ Participant's idea about nature of DM } & $\begin{array}{l}\text { Decrease in the response of body tissue to } \\
\text { insulin }\end{array}$ & 150 & 21.4 \\
\hline & Partial or total insulin secretion & 421 & 60.0 \\
\hline & Excess sweet eating & 87 & 12.4 \\
\hline & Don't know & 44 & 6.3 \\
\hline
\end{tabular}

Table 3. Participant's knowledge about risk factors, treatment and preventive measures of DM, Arar, 2016

\begin{tabular}{|l|l|l|l|}
\hline Items of questionnaire & Frequency $(\mathrm{n}=702)$ & $\%$ \\
\hline \multirow{3}{*}{$\begin{array}{l}\text { Risk factors of DM (Participant's } \\
\text { knowledge) }\end{array}$} & Hypertension & 26 & 3.7 \\
\cline { 2 - 4 } & Previous gestational diabetes & 32 & 4.6 \\
\cline { 2 - 4 } & Aging & 25 & 3.6 \\
\cline { 2 - 4 } & Lack of exercise and obesity & 342 & 48.7 \\
\cline { 2 - 4 } & Genetics & 233 & 33.2 \\
\cline { 2 - 4 } & Don't know & 44 & 6.3 \\
\hline \multirow{4}{*}{$\begin{array}{l}\text { DM treatment (Participant's } \\
\text { knowledge) }\end{array}$} & Only medication & 16 & 2.3 \\
\cline { 2 - 4 } & Only healthy diet & 10 & 1.4 \\
\cline { 2 - 4 } & Healthy diet and medication & 70 & 10.0 \\
\cline { 2 - 4 } & Healthy diet, exercise and medication & 606 & 86.3 \\
\hline \multirow{3}{*}{ DM preventive measures } & Stop alcohol and smoking & 17 & 2.4 \\
\cline { 2 - 4 } & Keep normal BP & 50 & 7.1 \\
\cline { 2 - 4 } & Weight loss and modification of life style & 443 & 7.4 \\
\cline { 2 - 4 } & Don't know & 52 & 19.9 \\
\cline { 2 - 4 } & Exercise five times weekly. & 140 & \\
\hline
\end{tabular}


Table 4 shows the knowledge of DM complications, as shown in the table, $24.5 \%$ of participants knew about retinopathy and loss of vision, $8.3 \%$ knew about retinopathy, loss of vision, low sensation and numbness in extremities, $1.6 \%$ knew about retinopathy, loss of vision ,low sensation and numbness in extremities, reduced immunity and increased incidence of infections. The most frequent answer $(24.9 \%)$ when we asked about the symptoms of DM was thirst and frequent urination. Table 5 shows participant's suffering from other chronic diseases and family history of DM, a low percentage (only 5.4\%) suffered from asthma, 3.27\% from hypertension, $2.3 \%$ have hypercholesterolemia and $2.1 \%$ suffered from peptic ulcer. A considerable number of the participants have family history of DM, $2.8 \%$ of the participants have both parents suffering from DM and $12.7 \%$ have only their father diseased.

Table 4. Knowledge of the participants about DM complications and symptoms

\begin{tabular}{|c|c|c|c|}
\hline \multicolumn{2}{|c|}{ Items of questionnaire } & \multirow{2}{*}{$\begin{array}{l}\text { Frequency } \\
(\mathrm{n}=702) \\
172\end{array}$} & \multirow{2}{*}{$\begin{array}{l}\% \\
24.5\end{array}$} \\
\hline \multirow{6}{*}{$\begin{array}{l}\text { DM } \\
\text { complications }\end{array}$} & Retinopathy and loss of vision & & \\
\hline & Retinopathy and loss of vision, low sensation and numbness in extremities & 58 & 8.3 \\
\hline & $\begin{array}{l}\text { Retinopathy and loss of vision, low sensation and numbness in extremities, } \\
\text { reduced immunity, increased incidence of infectious rate. }\end{array}$ & 11 & 1.6 \\
\hline & Retinopathy and loss of vision, chronic kidney disease & 20 & 2.8 \\
\hline & $\begin{array}{l}\text { Low sensation and numbness in extremities, retinopathy and loss of vision, } \\
\text { chronic kidney disease }\end{array}$ & 30 & 4.2 \\
\hline & $\begin{array}{l}\text { Retinopathy and loss of vision, chronic kidney disease, low sensation and } \\
\text { numbness in extremities and reduced immunity, increased incidence of } \\
\text { infectious rate }\end{array}$ & 13 & 1.8 \\
\hline \multirow{5}{*}{$\begin{array}{l}\text { Symptoms of } \\
\text { DM }\end{array}$} & Thirst and frequent urination & 175 & 24.9 \\
\hline & Thirst and frequent urination, poor wound healing & 28 & 4.0 \\
\hline & Thirst and frequent urination, poor wound healing, blurred vision & 37 & 5.3 \\
\hline & Thirst and frequent urination, increase of appetite to eat with loss of weight & 7 & 1.0 \\
\hline & $\begin{array}{l}\text { Thirst and frequent urination, increase of appetite to eat with loss of weight, } \\
\text { poor wound healing }\end{array}$ & 11 & 1.6 \\
\hline
\end{tabular}

Table 5. Participants suffering from other chronic diseases and family history of DM, Arar, 2016

\begin{tabular}{|l|l|l|l|}
\hline Items of questionnaire & Frequency $(\mathrm{n}=702)$ & $\%$ \\
\hline \multirow{5}{*}{ Chronic diseases } & Hypercholesterolemia & 16 & 2.3 \\
\cline { 2 - 4 } & Heart disease and hypercholesterolemia & 3 & 0.4 \\
\cline { 2 - 4 } & Heart disease, hypercholesterolemia and asthma & 2 & 0.3 \\
\cline { 2 - 4 } & Hypertension. & 23 & 3.27 \\
\cline { 2 - 4 } & Heart disease and hypertension & 2 & 0.3 \\
\cline { 2 - 4 } & Hypertension and hypercholesterolemia & 6 & 0.85 \\
\cline { 2 - 4 } & Asthma & 38 & 5.4 \\
\cline { 2 - 4 } & Peptic ulcer & 15 & 2.1 \\
\hline Family history of DM & Father & 29 & 0.3 \\
\cline { 2 - 4 } & Father, brother & 2 & 0.3 \\
\cline { 2 - 4 } & Father, brother, sister, aunt and uncle & 2.8 \\
\cline { 2 - 4 } & Father, mother & 10 & 0.6 \\
\cline { 2 - 4 } & Father, mother, brother & 4 & 1.4 \\
\cline { 2 - 4 } & Father, mother, brother, sister & 2.7 \\
\hline
\end{tabular}

\section{Discussion}

The study was carried out to evaluate the awareness of DM among the Saudi population in Arar, Northern Saudi Arabia. The findings of our study will help physicians to focus more on counseling the family members of diabetic patients on lifestyle modifications that will prevent the onset of diabetes or postpone the complications in the population. The specific objective of this study was to assess the awareness and knowledge of various aspects of diabetes mellitus and its complications among the Arar community. A total of 702 participants (501 females and 201 males) were counted. About $77.8 \%$ of them were highly educated. A total of $11.4 \%$ of the sample was diabetic. This was a low percentage if compared with the study of Khalid Alqurashi et al. which showed that $30 \%$ of the studied 
population had DM (8). This was close to Mansour M. Al-Nozha et al. studies, which found $23.7 \%$ of the studied population had DM (9). Our finding is less than that reported prevalence data from the Gulf region in Bahrain $(25.7 \%)$ and Oman $(16.1 \%)(10,11)$. Environmental factors substantially contribute and are closely related to the development of DM (12). Additionally, it was noted that as the educational level increases, the likelihood of regular exercise also increases. About lifestyle; only $12.7 \%$ did regular walking and exercise and $58.5 \%$ irregularly. A study conducted in India found that among the study subjects $48 \%$ followed dietary modifications to prevent diabetes. The Indian Diabetic Risk Score (IDRS) guidelines were used to assess physical activity at workplace, home and involvement in physical exercise. Most of them had a sedentary to mild physical activity pattern, $47 \%$ did not undertake any physical exercise (13). Furthermore $92.3 \%$ of participants had a diabetic relative or friend. Another study in Turkey (14) showed less percentage (57.5\%). A study conducted on African Americans reported that $95 \%$ of the cases had a diabetic relative (15). Our study showed that only $64.2 \%$ of the participants had sufficient knowledge about diabetes. About knowledge $21.4 \%$ of them knew that DM was caused by decrease in tissue response to insulin, $60 \%$ knew that it was a cause of partial insulin secretion and 12.4 thought it was caused by excess sweet eating. About knowledge of DM risk factors, $48.7 \%$ knew that lack of exercise and obesity were risk factors of DM, 33.2\% knew it was genetic and only 3.7\% knew that hypertension was a risk factor. In a Foma et al. study, the results showed that of the 199 participants, only 47\% said they knew what DM was. By, the same token, $53 \%$ of the participants in the study were unaware of the causes of DM and around $50 \%$ were unsure of the methods of prevention. Additionally, $67 \%$ knew that DM could result in loss of sight while $46.5 \%$ knew that DM could cause insufficient wound healing (16). In this study $86.3 \%$ said that healthy diet, exercise and medication were the best treatments for DM and $63.1 \%$ thought that weight loss and change to life style was the best preventive way. In the study by Foma et al. (16), almost half of the study participants had no clue on how the condition could be prevented while a very small number thought that weight loss $(0.5 \%)$ and exercise $(5.6 \%)$ were important measures in preventing the condition. Similar observations have been reported from India (17), Oman (18) and Tanzania (19). Participants knew the complications of DM like retinopathy (24.5\%) and loss of vision, retinopathy (8.3\%) loss of vision, low sensation and numbness in extremities, reduced immunity and increased incidence of infectious rate. In another study, few respondents knew that DM could lead to kidney failure (13.5\%), skin sepsis (12.0\%), heart failure (5.5\%) and stroke (4.5\%) (16). The most frequent answer when we asked about the symptoms of DM was thirst and frequent urination as $24.9 \%$ of participants agreed that it was the main symptom of the disease.

\section{Conclusions}

Diabetes mellitus poses a major health challenge both epidemiologically and economically in Arar, KSA. However, awareness of this pathological condition among diabetics is low in many Saudi settings, let alone the general population. Our study shows that the majority of participants have poor knowledge on several aspects of the condition including its causes, complications, management and prevention. Hence there is an urgent need to raise the level of awareness of this silent but deadly condition in the Saudi population.

\section{Acknowledgments:}

This study received no funding source but authors want to thank the administering primary health care centers who helped us in data collection. Also, authors would like to thank Arwa Nughaymish Alanazi and Amjad Hamoud Alruwaili who helped us in different steps of research.

\section{Conflict of Interest:}

There is no conflict of interest to be declared.

\section{Authors' contributions:}

All authors contributed to this project and article equally. All authors read and approved the final manuscript.

\section{References:}

1) International diabetes federation. IDF Diabetes Atlas. 5th edition. Available from: https://www.idf.org/elibrary/epidemiology-research/diabetes-atlas/20-atlas-5th-edition.html

2) Al Mazrou Y, Al-Shehri S, Manahar RAO. Ministry of Health. Kingdom of Saudi Arabia: Principles and Practice of primary health care. Health Education; 2002: 14-7.

3) Alberti KG, Zimmet PZ. Definition, diagnosis and classification of diabetes mellitus and its complications. Part 1: diagnosis and classification of diabetes mellitus. Provisional report of a WHO consultation. Diabet Med. 1998; 15(7): 539-53. doi: 10.1002/(SICI)1096-9136(199807)15:7<539::AID-DIA668>3.0.CO;2-S. 
4) Guariguata L, Whiting D, Weil C, Unwin N. The international diabetes federation diabetes atlas methodology for estimating global and national prevalence of diabetes in adults. Diabetes Res Clin Pract. 2011; 94(3): 322-32. doi: 10.1016/j.diabres.2011.10.040. PMID: 22100977.

5) Vandenheede H, Deboosere P, Gadeyne S, De Spiegelaere M. The associations between nationality, fertility history and diabetes-related mortality: a retrospective cohort study in the Brussels-Capital Region (2001-2005). J Public Health. 2012; 34(1): 100-7. doi: 10.1093/pubmed/fdr045. PMID: 21665909.

6) Hall V, Thomsen R, Henriksen O, Lohse N. Diabetes in Sub Saharan Africa 1999-2011: Epidemiology and public health implications. A systematic review. BMC Public Health. 2011; 11(1): 564-76. doi: 10.1186/1471-2458-11-564. PMID: 21756350, PMCID: PMC3156766.

7) Maina WK, Njenga EW, Muchemi EW. Knowledge, attitude and practices related to diabetes among community members in four provinces in Kenya: a cross-sectional study. Pan Afr Med J. 2010; 7(2): 15-8.

8) Alqurashi KA, Aljabri KS, Bokhari SA. Prevalence of diabetes mellitus in a Saudi community. Ann Saudi Med. 2011; 31(1): 19-23. doi: 10.4103/0256-4947.75773. PMID: 21245594, PMCID: PMC3101719.

9) Al-Nozha MM, Al-Maatouq MA, Al-Mazrou YY, Al-Harthi SS, Arafah MR, Khalil MZ, et al. Diabetes mellitus in Saudi Arabia. Saudi Med J. 2004; 25(11); 1603-10. PMID: 15573186.

10) Hamadeh RR. Noncommunicable diseases among the Bahraini population: A review. East Mediterr Health J. 2000; 6: 1091-7. PMID: 12197332.

11) Al-Lawati JA, Al Riyami AM, Mohammed AJ, Jousilahti P. Increasing prevalence of diabetes mellitus in Oman. Diabet Med. 2002; 19: 954-7. doi: 10.1046/j.1464-5491.2002.00818.x. PMID: 12421434.

12) Choi BC, Shi F. Risk factors for diabetes mellitus by age and sex: results of the National Population Health Survey. Diabetologia. 2001; 44: 1221-31. doi: 10.1007/s001250100648. PMID: 11692170.

13) Minmini S, Suvetha K. Focus on primary prevention: A study on awareness of diabetes mellitus and its complications among offsprings of diabetes patients. National Journal of Research in Community Medicine. 2016; 5(4): 196-201.

14) Oguzulusoy M, Argnkivanc S, Atakan M, Uzun O, BILGEÖZTÜRK-ŞAHIN, Okanolkaysu O, et al. Are Diabetic Patients Awar Of The Danger In Turkey? Acta Medica Mediterranea. 2016; 32: 925.

15) Baptiste-Roberts K, Gary TL, Beckles GL, Gregg EW, Owens M, Porterfield D, et al. Family History of Diabetes, Awareness of Risk Factors, and Health Behaviors Among African Americans. Am J Public Health. 2007; 97(5): 907-12. doi: 10.2105/AJPH.2005.077032. PMID: 17395839, PMCID: PMC1854868.

16) Foma MA, Saidu Y1, Omoleke SA, Jafali J. Awareness of diabetes mellitus among diabetic patients in the Gambia: a strong case for health education and promotion. BMC Public Health. 2013; 13: 1124. doi: 10.1186/1471-2458-13-1124. PMID: 24304618, PMCID: PMC3913398.

17) Hashmi NR, Seema D, Iram M. Awareness among individuals attending out Patient department of ghurki trust teaching hospital. Professional Med J. 2008; 15(1): 96-100.

18) Al Shafaee M, Al-Shukaili S, Rizvi S, Al Farsi Y, Khan M, Ganguly S, et al. Knowledge and perceptions of diabetes in a semi-urban Omani population. BMC Public Health. 2008; 8(1): 249. doi: 10.1186/14712458-8-249. PMID: 18644163, PMCID: PMC2517595.

19) Avi B, Colford J. Prevalence and Treatment of Diabetes in Rural Tanzania. Berkeley: University of California at Berkeley; Press; 2012. 